\title{
De las prácticas tradicionales a la supervisión médica en el ejercicio de la maternidad. Asturias 1900-1931
}

\section{Sonia García Galán (*)}

$\left(^{*}\right)$ Universidad de Oviedo. sonigalan@gmail.com

Dynamis

[0211-9536] 2011; 31 (1): 131-157
Fecha de recepción: 25 de enero de 2010

Fecha de aceptación: 4 de noviembre de 2010

SUMARIO: 1.- Introducción. 2.-La redefinición de la maternidad en la época contemporánea. 3.-La debatida cuestión de la lactancia. 4.-Prácticas tradicionales de crianza infantil. 5.-Normalizar el cuidado infantil. 6.-A modo de conclusión.

RESUMEN: Las primeras décadas del siglo XX constituyen una etapa de transición en la consideración de la maternidad y respecto al modo de afrontar la crianza. Todavía con un gran peso de las prácticas tradicionales de cuidado infantil, van tomando fuerza nuevas pautas establecidas por el colectivo médico, que tratará de que sean interiorizadas por las madres, sirviéndose para ello de iniciativas de diverso tipo. Las mujeres asumirán estos discursos pero serán capaces de readaptarlos conforme a sus situaciones y necesidades particulares.

PALABRAS CLAVE: Maternidad científica, puericultura, crianza, lactancia materna, madres.

KEY WORDS: Scientific motherhood, childcare, upbringing, breastfeeding, mothers.

\section{Introducción $\left(^{*}\right)$}

La maternidad ha constituido históricamente una pieza central de la feminidad. Sin embargo, tanto la construcción simbólica del hecho materno como el propio ejercicio de esta función por parte de las mujeres no ha permanecido inmutable sino, más bien al contrario, se ha ido readaptando y

(*) Este artículo forma parte del de mi trabajo en el Proyecto de Investigación financiado por el Ministerio de Ciencia e Innovación "Claves diacrónicas de la divergencia social entre las construcciones simbólicas y las construcciones jurídicas de la maternidad» (HAR-2009-10035 subprograma HIST). 
reelaborando con el paso del tiempo. La importancia de abordar el estudio de la cuestión materna a la hora de estudiar y tratar de comprender el pasado de las mujeres debe ser, por tanto, puesta de manifiesto. En este sentido, desde el campo de la historia de las mujeres y del género, la maternidad ha sido analizada desde múltiples puntos de vista ${ }^{1}$.

El artículo que presentamos trata de acercarnos a las prácticas maternas en el marco asturiano. Partiendo de la premisa de que «la forma de concebir la maternidad no ha sido algo decidido por las propias mujeres, sino impuesto por el poder masculino» ${ }^{2}$, pretendemos contrastar discursos y prácticas para comprender las transformaciones que se produjeron en las primeras décadas del siglo pasado en el modo de concebir y afrontar el hecho materno. Hay dos aspectos fundamentales hacia los que dirigimos nuestro análisis: en primer lugar, pretendemos contraponer la imagen de la «madre ideal» con las prácticas de las «madres reales» tanto de los estratos acomodados como de los medios obreros y campesinos. En segundo término, nos proponemos estudiar las tácticas y recursos empleados desde el colectivo médico para normalizar el cuidado de las criaturas por sus madres, tratando de valorar, a través de las fuentes disponibles, su grado de éxito. Para ello tendremos en cuenta, además de la perspectiva de género, la variable de clase social y el ámbito geográfico, rural o urbano, del que se trate.

En relación con el tema que proponemos se han realizado en los últimos años interesantes trabajos como los de Denyse Baillargeon y Catherine Rollet en Canadá y Francia respectivamente, el estudio de Lara Marks centrado en la ciudad de Londres o el análisis de Rima Apple sobre Estados Unidos ${ }^{3}$.

1. Bolufer, Mónica. Madres, maternidad: nuevas miradas desde la historiografía. In: Franco Rubio, Gloria, ed. Debates sobre la maternidad desde una perspectiva histórica (siglos XVI-XX). Barcelona: Icaria; 2010, p. 51-81; Badinter, Elisabeth. ¿Existe el instinto maternal? Historia del amor maternal. Siglos XVII al XX. Barcelona: Paidós; 1991; Thébaud, Françoise. Quand nos grand-mères donnaient la vie. La maternité en France dans l'entre-deuX-guerres. Lyon: Presses Universitaires de Lyon; 1986; Amelia, Marina d’, ed. Storia della maternitá. Roma: Laterza; 1997; Bock, Gisela; Thane, Pat, eds. Maternidad y políticas de género. Madrid: Cátedra; 1996; Nash, Mary. Maternidad, maternología y reforma eugénica en España. In: Duby, George; Perrot, Michelle, dirs. Historia de las mujeres en Occidente. Vol. 5, El siglo XX. Madrid: Taurus; 1993, p. 627-646.

2. Cid, Rosa. Introducción. In: Maternidad/es: representaciones y realidad social. Edades Antigua y Media. Sevilla: Almudayna; 2010, p. 10.

3. Baillargeon, Denyse. Un Québec en mal d'enfants. La medicalisation de la maternité 1910-1970. Montreal: Les ediciones du remue-menage; 2004; Rollet, Catherine. History of the health notebook in France: A stake for mothers, doctors and state. Dynamis. 2003; 23: 143-166; Marks, Lara V. Metropolitan maternity: maternal and infant welfare services in early twentieth 
En España, junto a las aportaciones de autoras como Irene Palacio o Mary Nash, la cuestión de la crianza ha sido ampliamente estudiada desde la perspectiva de la historia de la infancia, la medicalización de la vida infantil y la lucha contra las tasas de mortalidad entre las criaturas ${ }^{4}$. Perspectiva ésta en la que la maternidad no constituía el centro de los análisis, sino que más bien era tratada como un tema que emergía, necesariamente, al pretender estudiar y conocer la atención de niños y niñas.

En el artículo abordamos el proceso de medicalización de la maternidad en los comienzos del siglo pasado desde una aproximación que prima lo empírico frente a las elucubraciones teóricas. Tratamos de analizar, desde la cercanía que permite un estudio regional, el modo en los médicos - varones en su mayoría - fueron implementando su concepción de la maternidad sobre las mujeres y observar las pequeñas resistencias que presentaron aquéllas en este proceso.

Hemos recurrido a fuentes de diverso tipo, entendiendo que cada una aporta una mirada distinta que nos ayuda a configurar una visión poliédrica del pasado: junto a las fuentes más habituales en el estudio de los procesos de medicalización de la maternidad y la infancia, como tratados de higiene infantil o revistas publicadas desde el higienismo y la medicina, hemos sumado otras menos exploradas, como las topografías médicas. Para el periodo que nos ocupa y referidas a Asturias, hemos consultado doce topografías que nos han aportado informaciones interesantes sobre espacios geográficos dispares, desde el centro, a las zonas oriental y occidental de la región. Estas fuentes se han complementado con la documentación del Instituto de Puericultura de Gijón y con una amplia consulta de la prensa regional. Aunque nuestro análisis se servirá sobre todo de textos producidos por

century London. Amsterdam: Rodopi; 1996; Apple, Rima. Constructing mothers: scientific motherhood in the nineteenth and twentieth centuries. Social History of Medicine. 1995; 8 (2): 161-178.

4. Palacio Lis, Irene. Mujeres ignorantes: madres culpables. Adoctrinamiento y divulgación maternoinfantil en la primera mitad del siglo XX. Valencia: Universitat de Valencia; 2003; Nash, n. 1; Rodríguez Ocaña, Esteban; Perdiguero, Enrique. Ciencia y persuasión social en la medicalización de la infancia en España, siglos XIX y XX. História, Ciencias, Saúde - Manguinhos. 2006; 13 (2): 303-324; Borrás Llop, José María, dir. Historia de la infancia en la España Contemporánea 1834-1936. Madrid: Ministerio de Trabajo y Asuntos Sociales; 1996; Ballester, Rosa; Balaguer, Emilio. La infancia como valor y como problema en las luchas sanitarias de principios de siglo en España. Dynamis. 1995; 15: 177-192. 
médicos ${ }^{5}$, trataremos de recuperar las voces y testimonios de las mujeres, a través de los artículos que publicaron en revistas y en la prensa diaria.

\section{La redefinición de la maternidad en la época contemporánea}

El cambio en la concepción de la maternidad en la época contemporánea hunde sus raíces en el XVIII, un siglo de intensos debates sobre la naturaleza femenina ${ }^{6}$. En ese debate, las posiciones defendidas por Rousseau y compartidas por otros pensadores y por médicos, afirmaban que las mujeres estaban condicionadas por su cuerpo ${ }^{7}$. Esa diferencia esencial, implicaba que debían consagrar su existencia a cumplir con el papel asignado por naturaleza, siendo tiernas y abnegadas madres y esposas. Si bien es cierto que el discurso roussoniano recogía elementos de la feminidad cristiana, incorporaba también ideas novedosas. La mujer, como en los siglos precedentes, seguía vinculada a la maternidad, pero sobre las nuevas bases de la ciencia y con unas connotaciones originales: el nuevo modelo de madre no era una mujer pasiva, sino diligente, activa y responsable, educada para la vida doméstica y que no delegaba el cuidado de sus hijos e hijas a terceras personas ${ }^{8}$. Cabe reseñar, no obstante, que estos discursos iban dirigidos a una minoría de mujeres de las clases acomodadas y suficientemente instruidas como para poder leer los textos médicos de divulgación y los tratados de economía doméstica que se editaban ya con cierta profusión en el siglo XVIII ${ }^{9}$.

Conforme avanza la modernidad, este modelo maternal experimenta una serie de cambios de forma paralela a la ampliación de sus destinatarias. A finales del siglo XIX, en Europa, Norteamérica y en algunos países de Latinoamérica, emerge un notable interés por el modo en que las madres se ocupan de sus hijas e hijos, muy vinculado a la mayor consideración de

5. Cuando empleamos el término «médicos» nos referimos a varones.

6. Morant, Isabel; Bolufer, Mónica. Amor, matrimonio y familia. Madrid: Síntesis; 1998, p. 195; Amorós, Celia; Cobo, Rosa. Feminismo e Ilustración. In: Amorós, Celia; De Miguel, Ana, eds. Teoría feminista: de la llustración a la globalización. Vol. 1, De la llustración al segundo sexo. Madrid: Minerva; 2005, p. 91-144; Puleo, Alicia. La Ilustración olvidada. La polémica de los sexos en el siglo XVIII. Madrid: Anthropos; 1993.

7. Morant, n. 6, p. 197. Amorós, n. 6, p. 132-144.

8. Morant, n. 6, p. 223. Badinter, n. 1, p. 117-119.

9. Morant, n. 6, p. 192. 
la infancia como un elemento esencial para el progreso y la riqueza de las naciones ${ }^{10}$. La idea tenía mucho que ver con la necesidad de proveer mano de obra a la industria, pero también con las mentalidades en un periodo de auge del imperialismo, en el que se relacionaba la grandeza de cada país con su grado de expansión territorial y su número habitantes. La identificación entre desarrollo nacional y bienestar infantil habría calado en la opinión pública asturiana en los comienzos del XX a tenor de las informaciones que hemos recogido de la prensa:

«importa mucho a los pueblos el concurso de generaciones higiénicamente preparadas para la robustez y la salud, que son la base de la preponderancia industrial, científica y política de las naciones» ${ }^{11}$.

Directamente relacionada con la concepción de la infancia como fuente esencial de riqueza y prosperidad nacional, encontramos la intensa lucha emprendida en aras del descenso de la mortalidad infantil, percibida como un grave problema social en países como Francia, Canadá, Inglaterra, Chile, Argentina, Uruguay o España entre otros ${ }^{12}$. La modernidad conectaba, con una rapidez desconocida hasta entonces, lugares alejados haciendo que los debates públicos adquirieran resonancia internacional. Como una de las principales contrapartidas de este proceso de revalorización de la vida infantil, la maternidad recibía también más atención. Desde la medicina, los medios higienistas se ocuparon con profusión de la cuestión materna. Pertenecientes a las clases medias, los higienistas eran por lo general reformistas y como tales estaban conformes con el orden liberal-burgués

10. La imagen que se tiene de la infancia en torno al cambio de siglo supone un desarrollo, según algunas investigaciones un cambio cualitativo en la construcción ilustrada de la imagen de las criaturas, en lo que Ariès denominó descubrimiento de la infancia. Aún quienes no admiten la tesis de Ariès reconocen que en el mundo contemporáneo se han registrado cambios notables en relación a la consideración de niños y niñas. Ballester, n. 4, p. 179; Rodríguez Ocaña, Esteban. La salud infantil, asunto ejemplar en la historiografía contemporánea. Dynamis. 2003; 23: 27-36 (28).

11. Un sanatorio ginecológico. El Carbayón. 6 Ene 1915.

12. Variot, Gastón. Tratado de higiene infantil. Madrid: Saturnino Calleja Fernández; s.a.; Baillargeon, n. 3; Marks, n. 3; Lavrin, Asunción. Mujeres, feminismo y cambio social en Argentina, Chile y Uruguay, 1890-1914. Santiago de Chile: Centro de Investigaciones Diego Barros Arana; 2005, p. 134-138; Rodríguez Ocaña, Esteban. Una medicina para la infancia. In: Borras Llop, n. 4, p. 149-183; Rodríguez Ocaña, Esteban; Ortiz Gómez, Teresa; García-Duarte, Olga. Los Consultorios de Lactantes y Gotas de Leche en España. Jano. Medicina y Humanidades. 1985; 663-H: 1066-1072. 
pero al tiempo, eran partidarios de aplicar medidas que mejorasen las condiciones de vida del proletariado y solucionasen la problemática y temida «cuestión social» ${ }^{13}$. En esta labor, las mujeres y particularmente las madres, recibieron un cometido: ordenar los hábitos de vida a través del hogar y la familia, para lo cual debían ser formadas en los presupuestos de la Economía doméstica y la Puericultura. La nueva concepción materna se corresponde con una «madre científica» que si bien compartía algunas cualidades con el modelo de Rousseau, como la abnegación y la dedicación a su familia, suponía la introducción de dos novedades esenciales: la nueva madre ideal pertenecía a las clases medias (no era aristócrata ni de la alta burguesía) y para criar a sus hijos e hijas con éxito - evitando su muerte y procurando un aspecto saludable-debía someterse a la ciencia y seguir el consejo médico experto ${ }^{14}$.

Este proceso de redefinición de la función materna experimentó un cambio tanto cualitativo como cuantitativo coincidiendo con el final de la Gran Guerra, conflicto que supuso una verdadera conmoción en los roles de género ${ }^{15}$. Para tratar de restaurar a las mujeres en sus hogares, temporalmente abandonados en la contienda, la ciencia médica redoblará sus esfuerzos recordando a las mujeres que la «naturaleza» establecía que su papel social era el de ser madres y que su lugar estaba en el espacio doméstico. En este sentido, son conocidas las teorías de Marañón (18871960) sobre la complementariedad de los sexos y el alto grado de consenso que alcanzaron ${ }^{16}$. No es casual, por tanto, que en los años veinte veamos multiplicarse en los diarios asturianos los artículos sobre el valor de la infancia y la importancia la función materna. En ellos se sigue insistiendo en la necesidad de poner freno a la mortalidad infantil, pero se suman otros elementos, como la preocupación por el descenso de la natalidad que, si bien se había despertado en Francia unos años atrás, calaba en España en la

13. Morata, Eva. La imagen de la maternidad en la España de finales del siglo XIX y principios del XX. Arenal. 2003; 10 (2): 163-168.

14. Apple, n. 3, p. 161.

15. Thébaud, Françoise. La Primera Guerra Mundial: ¿la era de la mujer o el triunfo de la diferencia sexual? In: Duby, Perrot, eds., n. 1, p. 31-90. García Galán, Sonia. Mujeres modernas, madres conscientes y sufragistas exaltadas. Ideales de feminidad y debates feministas en Asturias (1919-1931). Oviedo: KRK; 2009, p. 259-283.

16. Nash, n. 1, p. 629; Nash, Mary. Maternidad y construcción identitaria: debates sobre el siglo XX. In: Franco, n. 1, p. 28; Aresti, Nerea. Médicos, donjuanes y mujeres modernas. Los ideales de feminidad y masculinidad en el primer tercio del siglo XX. Bilbao: Universidad del País Vasco; 2001. 
década de $1920^{17}$. La caída de la tasa de natalidad era percibida con especial recelo en los grupos católicos y conservadores: «la crisis de la natalidad se extiende por todo el mundo» afirmaba Pedro Sangro en una conferencia pronunciada en la Semana Social de Oviedo, en $1926^{18}$. Esta cuestión ocupó un lugar notable en el debate público derivando en las medidas pronatalistas impulsadas durante la dictadura de Primo de Rivera ${ }^{19}$. Sin embargo, el elemento que más relevancia adquirió en la concepción de la maternidad en los años veinte fue la preocupación por la calidad de las nuevas generaciones o eugenesia. La doctrina eugénica contaba con una amplia aceptación en los medios reformadores y progresistas de la época y suponía para las madres, además de procurar la supervivencia de sus criaturas, asegurarse de su salud y fortaleza física. La madre que incumplía este nuevo mandato, en palabras del médico Avelino González (1893-1964) «falta a los deberes primordiales para los que fue creada, desde el momento en que es mujer, cuyos deberes son: la conservación y la mejora de la especie» ${ }^{20}$.

La definición y reelaboración de la maternidad en la época contemporánea fue un proceso que se vivió con carácter general en Europa y en buena parte del continente americano. Sin embargo, el desarrollo concreto con el que se llevó a cabo en la práctica tuvo que ver con los contextos sociales, económicos, políticos y demográficos de cada país o región. En las páginas que siguen vamos a tratar de exponer y valorar de qué modo se implantó el nuevo modelo de la «maternidad científica» en Asturias.

\section{La debatida cuestión de la lactancia}

El nuevo ideal maternal que comenzó a gestarse en las postrimerías del XVIII concedió una especial relevancia a la lactancia materna. Algunos pensadores ilustrados, imbuidos de ideas poblacionistas, establecieron ya

17. Thébaud, n. 1, p. 13-23.

18. Sangro, Pedro. Importancia de las familias numerosas y cómo protegerlas. In: Arboleya, Maximiliano. Estudio y defensa de la familia cristiana. Crónica y lecciones. Semana Social de Oviedo. Oviedo: Editorial Covadonga; 1926, p. 149.

19. La periodista Mercedes Valero, de convicciones católicas y conservadora, se vanagloriaba en el diario Región de la aprobación del decreto que concedía una ayuda efectiva a las familias numerosas, además de matrícula gratuita para sus hijos e hijas en todos los centros de enseñanza oficial. Mercedes Valero. Un jirón de azul. Región. 24 Jun 1926.

20. González, Avelino. La Gota de Leche. El Instituto de Seroterapia. La madre. 21 Oct 1919. 
entonces una relación entre la alta mortalidad infantil y la crianza de criaturas a cargo de amas de cría y fuera del domicilio familiar. Junto a estas argumentaciones se mezclaron otras de carácter moral, insertadas en un discurso de género que conminaba a las madres a prodigar todo tipo de atenciones a sus vástagos. En este sentido, el hecho de enviar a las criaturas a criar a la aldea suponía una dejación en toda regla de los renovados deberes maternales ${ }^{21}$. Pese a que estos discursos ilustrados tenían como principales destinatarias a las mujeres de las clases acomodadas, muchas de ellas continuaron recurriendo a nodrizas hasta bien entrado el siglo XX. En las tres primeras décadas del siglo pasado, las burguesas que no amamantaban a su prole eran criticadas con rudeza, acusadas de incumplir su cometido maternal bajo el pretexto, poco excusable a juicio de sus censores, de acudir a reuniones sociales o de mantener su figura. Médicos como Avelino González entendían que no existía «obligación moral y social mayor en una mujer que es madre, que dar, pudiendo, el pecho a su hijo» ${ }^{22}$. La maternidad demandaba total dedicación y amamantar formaba parte de las obligaciones inherentes al hecho de ser madre. Este era el argumento de fondo que sostuvo toda la campaña en favor de la lactancia materna si bien, como veremos, fue incorporando otros acentos.

En los comienzos del siglo XX la reflexión médica establece como explicación prioritaria de la mortalidad infantil, la incidencia de enfermedades gastrointestinales ${ }^{23}$ de manera que, para reducir sus cifras, demanda regular la alimentación. Esto supone promover la lactancia materna pero también controlarla, supervisarla y normalizarla. Distintos foros habían debatido y llegado a la conclusión de que la mortalidad era más elevada en las criaturas cuando eran enviadas a criar a las aldeas. Uno de estos foros fue el Congreso de Medicina celebrado en 1913 en Londres en el que el doctor Wallich, profesor de la Facultad de Medicina de París, presentó un informe concluyendo que en la capital francesa morían más las criaturas que eran lactadas «lejos de la madre» ${ }^{24}$. Pese a la publicación de estos datos y pese a la reprobación médica a la lactancia fuera del domicilio familiar (donde las madres no podían supervisar el cuidado que se dispensaba a sus

21. Morant, n. 6, p. 227. Saraúsa, Carmen. Criados, nodrizas y amos. El servicio doméstico en la formación del mercado de trabajo madrileño, 1758-1868. Madrid: Siglo XXI; 1994, p. 187-193.

22. González, n. 20.

23. Rodríguez Ocaña, 1996, n. 12, p. 149.

24. Maternología. Cultura e Higiene. 13 Dic 1913. 
criaturas por parte de las nodrizas) a comienzos del siglo pasado aún era frecuente en Asturias recurrir a una nodriza externa, generalmente en la aldea $^{25}$. Empleaban esta modalidad familias en las que la madre no podía lactar y que no disponían de ingresos suficientes para afrontar el elevado coste que suponía contratar a una nodriza interna. Existían también nodrizas que ejercían su oficio en su casa dentro de la propia ciudad, ofertando el servicio a menor precio con destino a madres obreras, sirvientas o nodrizas internas, que no podían compatibilizar sus trabajos con la crianza. Todos los médicos coincidían en rechazar esta modalidad de lactancia argumentando la mortalidad derivada de tal práctica. Sin embargo, éste no era un argumento totalmente objetivo, sino que se unía a él la consideración moral de que la criatura debía estar al lado de su madre. Para corregir la alta mortalidad derivada de la crianza externa podían haberse promovido otro tipo de medidas como, por ejemplo, instruir a las nodrizas. Sin embargo, la solución aportada desde la medicina pasaba por erradicar esta práctica y hacer que las madres se ocuparan personalmente de la lactancia.

Otra de las modalidades de crianza era la de contratar a una nodriza interna. Los costes derivados de pagar y mantener a un ama de cría eran elevados, siendo ésta una de las razones fundamentales para entender el prestigio que otorgaba contar con una mujer dedicada a estos menesteres ${ }^{26}$. Si para repudiar el recurso a las nodrizas externas les bastaba con esgrimir las cifras de mortalidad infantil entre las criaturas que crecían lejos de su domicilio familiar, para combatir el recurso a nodrizas internas tuvieron que recurrir a otras argumentaciones. En primer lugar, se insistía en la lógica de la nueva concepción materna: la mujer que no amamantaba no era «verdaderamente» madre: «es más madre la que cuida y cría que la que se limita a parir», sentenciaba Honorio García Álvarez ${ }^{27}$. Este supuesto se aplicaba tanto a las madres que contrataban nodrizas como a las propias amas que dejaban a su criatura a cargo de otras personas (abuelas, hermanas $u$ otras nodrizas). La segunda argumentación pasaba por descalificar a

25. Nos consta la existencia de nodrizas que crían en su casa por los anuncios publicados en la prensa en los que se ofrecen «para criar en su casa» y por los expedientes consultados en el documento Solicitudes de admisión en la Gota de Leche. Archivo Municipal de Gijón. «Fondo del Instituto de Puericultura».

26. Los sueldos de las amas de cría eran más elevados que los de otras sirvientas. Sarasúa, n. 21, p. 180.

27. Honorio García Álvarez. Al margen del hogar. Vulgarización médica a las madres. El Comercio. 27 Dic 1928. 
las amas de crías acusándolas de ser madres «desentrañadas» ${ }^{28}$ y de vivir rodeadas de lujos, comodidades y caprichos:

«Desde el momento en que la nodriza entra en una familia [sentenciaba Avelino González] casi se puede asegurar que la que ordena y manda es ella. Sus caprichos, sus menores deseos tienen que ser complacidos» ${ }^{29}$.

El elevado tono de censura hacia las nodrizas fue ampliamente compartido por el colectivo médico, aunque justo es señalar que hubo ciertas voces discordantes. En este sentido, Rafael Ulecia pensaba que las nodrizas eran dignas de una mayor consideración puesto que dejaban un hogar y una familia con apremiantes necesidades para «ahogar» sus sentimientos maternales y "poder ganar unas monedas». ${ }^{30}$ Esta visión más amable de la profesión de nodriza era compartida por algunos médicos que todavía a comienzos del XX preferían la nodriza al recurso al biberón; Rodríguez Ocaña cita a Vidal, Viura y Comenge en la primera década de siglo, pero todavía en 1912, Luis Azcoitia escribía un artículo en el diario El Carbayón aconsejando «que las madres de las clases acomodadas críen a sus hijos, y en caso de imposibilidad que busquen buena nodriza» ${ }^{31}$.

Pese a las opiniones discordantes, el recurso a nodrizas era criticado por la mayor parte de los médicos. Como alternativa a la lactancia «mercenaria», presentaban dos posibles opciones ${ }^{32}$. La primera pasaba por continuar promoviendo la lactancia materna, cuestión que, en los años veinte, había

28. Avelino González. La Gota de Leche. La nodriza. El Comercio. 25 Oct 1919.

29. Avelino González. La Gota de Leche. La nodriza II. El Comercio. 26 Oct 1919.

30. Ulecia y Cardona, Rafael. El arte de criar a los niños. Nociones de higiene infantil. Madrid: Adm. de la Revista de Medicina y Cirugía Prácticas; 1914, p. 65. Declaraciones del mismo doctor en este sentido, recogidas por Colmenar Orzaes, Carmen. Nodrizas y lactancia mercenaria en España durante el primer tercio del siglo XX. Arenal. 2007; 14 (2): 335-359 (339).

31. Luis Azcoitia. Especialista en las enfermedades de los niños. El Carbayón. 12 Ago 1912.

32. Hubo una tercera vía, la reglamentación del oficio de nodriza. Esta postura fue adoptada en Francia por la Ley Roussel en 1874 y, unos años más tarde, en el Congreso Internacional de Higiene y Demografía celebrado en Madrid en 1898, se apostó por aplicar medidas similares en todos los países. En España, la propuesta fue acogida por Manuel Tolosa Latour y llegó a derivar en medidas legislativas que trataban de garantizar el buen estado de salud de las mujeres dedicadas a este oficio, al ser consideradas agentes de contagio. Rodríguez Ocaña; Ortiz Gómez; García-Duarte, n. 12. Colmenar Orzaes, n. 30, p. 335-359. No obstante, estas medidas tuvieron un alcance limitado y pronto se vieron superadas por la propia erradicación del oficio de nodriza, que se producirá paralelamente a la disponibilidad de formas más seguras de lactancia artificial. 
tomado tintes eugénicos: «la lactancia materna tiene que imponerse para el bien de la raza» ${ }^{33}$. La segunda, por proveer leche en buenas condiciones a las madres que no podían amamantar. Este era el objetivo que perseguía la puesta en marcha, primero en Oviedo y posteriormente en Gijón, de sendas Gotas de Leche. Las Gotas de Leche tuvieron su origen en Francia en la última década del siglo XIX con el objeto de suministrar leche esterilizada destinada a la alimentación infantil. Desde este país se extendieron a Alemania, Gran Bretaña, Estados Unidos, y también a España, creándose la primera en Barcelona en 1902 34 . Para su organización en Oviedo habría que esperar algo más, inaugurándose en 1913. Una de las principales promotoras de la Gota de Leche ovetense fue la maestra María Asunción Izquierdo. Comprometida con el higienismo y confesa lectora de la obra de Rafael Ulecia (fundador de la primera Gota de Leche y Consultorio infantil de Madrid en 1904) publicó una serie de artículos en la prensa local en los que exponía «la necesidad de fundar en Oviedo una Gota de leche a semejanza de las que en otras capitales de España funcionan» ${ }^{35}$. La idea fue acogida con entusiasmo por el doctor Arturo Buylla (1852-1912) quien, desde la Junta local de Protección a la Infancia impulsó el proyecto. No obstante, el fallecimiento de éste supuso que otro médico, Manuel Estrada (1881-1972) tomase el relevo, haciéndose cargo de la dirección del centro. Para recaudar los fondos necesarios para organizar la Gota de Leche, se formó una Junta de Damas integrada por mujeres de la aristocracia y alta burguesía de la ciudad. La Gota de Leche funcionó en el ala izquierda del Hospicio Provincial. En la entrada de la misma se situó la sala de espera en cuya pared estaba colgado el retrato del Arturo Buylla, en reconocimiento a su labor como impulsor del proyecto, junto a unos cuadros con «consejos a las madres» ${ }^{36}$. Contaba asimismo con un gabinete de consulta donde Estrada examinaba a las criaturas y un local para esterilizar, lavar mecánicamente y llenar los biberones. Como personal, además del doctor Estrada, disponía de un practicante y dos monjas. El centro suministraba leche gratuita para

33. Honorio García Álvarez. Al margen del hogar. Vulgarización médica a las madres. El Comercio. 5 Ene 1929.

34. Rodríguez Ocaña, Ortiz Gómez, García-Duarte Ros, n. 12, p. 1067-1069. Las Gotas de Leche se extendieron también por países de América del Sur, como Chile, Uruguay o Argentina en la década de 1910. Lavrin, n. 12, p. 154.

35. Maria Asunción Izquierdo. Pro infancia. Una grata noticia para las madres. El Carbayón. 18 Dic 1911.

36. La Gota de Leche. El Carbayón. 18 Sep 1913. 
familias sin recursos, pero estaba pensado también para otras con medios económicos que tenían que pagar por el servicio.

Unos años más tarde, en 1925, se puso en funcionamiento otra Gota de Leche en Asturias, en este caso en la ciudad de Gijón. Aunque la finalidad era igualmente la de dispensar leche de vaca esterilizada para las madres que no podían amamantar, los presupuestos sobre los que se organizó este centro fueron, al menos en parte, diferentes a los que habían alentado el proyecto ovetense. El promotor de este centro fue Avelino González, médico asturiano que se había formado en Valladolid y que había completado sus estudios como especialista en Puericultura en Madrid, en el hospital de Enrique Suñer (1878-1941). La Gota de Leche de Gijón se organizó de forma paralela a un Consultorio infantil y formaba parte de un proyecto más ambicioso, el de constituir un Instituto de Puericultura, ideal que se llevó a efecto en diferentes fases a lo largo de los años veinte. El planteamiento de Avelino González tenía connotaciones más modernas que las que sustentaban el centro ovetense: se dotó de un edificio pensado y construido para tal fin, mientras que en el caso de Oviedo se utilizaron unos locales del Hospicio. Además, el proyecto de Gijón recurrió a personal especializado mientras que la Gota de Leche ovetense, era atendida, al igual que el Hospicio, por monjas. Esto revela un desfase en cuanto a los recursos disponibles pero muestra también dos concepciones distintas sobre lo que debían ser unas instalaciones de este tipo ${ }^{37}$.

Avelino González era un médico totalmente comprometido con la promoción de la lactancia materna y, sin embargo, se puso al frente de un dispensario de leche de vaca esterilizada lo que, a primera vista, puede resultar contradictorio. Para salvar la paradoja González recurría a las palabras del doctor francés Gustave Variot (1855-1905):

«Dice Variot que mientras no llegue una edad de oro que todos los especialistas esperamos, en que todas las madres de todas las clases sociales puedan dar el pecho a sus hijos, es deber de toda autoridad y de todo hombre de bien defender la vida de los pequeñuelos lactados artificialmente. (...) Mientras nuestras mujeres obreras tengan que trabajar fuera de casa y existan circunstancias sociales que no está en manos del médico cambiar,

37. García Galán, Sonia. Discursos médicos, prácticas cotidianas y visiones feministas de la maternidad en Asturias, 1919-1931. In: Suárez Suárez, Carmen, ed. Maternidades. (De) construcciones feministas. Oviedo: KRK; 2009, p. 123-124. 
habrá siempre un gran número de niños imposibilitados de lactarse al pecho y condenados por lo tanto al biberón» ${ }^{38}$.

Para González era una cuestión de extrema necesidad evitar, de este modo, la muerte de muchas criaturas que tomaban leche en malas condiciones y, a la vez, era un remedio para no tener que emplear a una nodriza. Sin embargo, es interesante recordar que este médico no estaba apostando porque las madres obreras pudieran compatibilizar trabajo asalariado y crianza sino que, muy al contrario, esperaba la «edad de oro» en que las mujeres no tuvieran que trabajar fuera de casa. Además, entendía que algunas se veían obligadas a trabajar por extrema necesidad pero no aceptaba que lo hicieran por su voluntad de ganar un salario o mejorar las condiciones de vida de la familia. En un expediente consultado en el registro de la Gota de Leche de Gijón observamos el caso de una obrera a la que le fue denegado el servicio alegando que puesto que «su marido ganaba bastante», ella debía dejar su empleo para dedicarse a amamantar a su criatura ${ }^{39}$.

Cabe plantearse hasta qué punto los médicos obtuvieron éxito en la campaña de promoción de la lactancia materna. Algunos autores entienden que sus resultados fueron «contradictorios puesto que la campaña puericultora condujo al aumento del biberón» ${ }^{40}$.

Es cierto que muchas madres van a recurrir a la lactancia artificial. Esta fórmula hacía posible compatibilizar la crianza con otros deberes y ocupaciones. María Izquierdo, que era madre además de maestra y articulista, reconocía la utilidad del biberón no sólo por razones médicas sino también por sentido práctico pues «no es raro tener que ausentarse de casa durante varias horas, cuando así lo exigen perentorias necesidades» y por ello recomendaba «acostumbrar al niño al biberón después de los dos primeros meses» ${ }^{41}$. La misma autora confesaba haber utilizado leche de vaca mezclada con agua para alimentar a sus criaturas «con muy satisfactorios resultados» ${ }^{42}$. Pese a ser buena conocedora de los consejos médicos sobre crianza infantil, la maestra asturiana asumía el discurso pero adaptándolo

38. González, Avelino. El Instituto de Puericultura, el Consultorio de niños de pecho y la Gota de Leche. El Comercio. 11 Ago 1922.

39. Solicitudes de admisión, n. 25.

40. Rodríguez Ocaña, Perdiguero, n. 4, p. 310.

41. María Izquierdo. A las madres. Del arte de criar niños IV. El Carbayón. 12 Feb 1909.

42. María Asunción Izquierdo. A las madres. Del arte de criar niños. Revista Popular de Higiene. 1910: 85. 
a su situación concreta y a sus necesidades particulares y, cabe pensar que como ella, otras mujeres, instruidas o no, actuarían en un sentido similar. Junto a todo lo dicho cabe añadir una última reflexión relativa a la lactancia que nos obliga, en gran medida, a reformular la pregunta respecto al éxito obtenido por la medicina en este campo. Las topografías médicas que hemos consultado dan cuenta de una serie de informaciones que generalmente no se incorporan al debate sobre esta cuestión. De estos estudios se desprende que en la mayor parte de la región las madres amamantaban a sus criaturas. Valentín Fernández, en la topografía del concejo de Tapia de Casariego publicada en 1932 afirmaba que «justo es reconocer que son muchas las madres que crían con sus pechos a sus hijos» y añadía «pero justo es igualmente decir que lo hacen de un modo completamente caprichoso y sin dirección alguna» ${ }^{43}$. Lo mismo se dice de las madres del concejo de Corvera donde «las que pueden lactan a sus hijos» ${ }^{44}$ y de Langreo: «la obrera cría siempre, y cuando no lo hace voluntariamente, es que el agobio, enfermedad intercurrente o nuevo embarazo se lo impide» ${ }^{45}$. Estos testimonios nos permiten concluir que la mayor parte de las mujeres campesinas y obreras lactaban a sus criaturas, sólo que no lo hacían conforme a las pautas decretadas por los médicos. Para el caso canadiense, Baillargeon afirma que muchas madres amamantaban, pero no durante tanto tiempo como los médicos consideraban que debían hacerlo. ${ }^{46}$ En Asturias más que una cuestión de tiempo era una cuestión de modo. García Álvarez explicaba con detalle en un artículo publicado en El Comercio, en 1929, como debían proceder las mujeres a la hora de amamantar:

«El número de pechos, horas, cantidad (...) lo regularéis por la cantidad prudencial de leche que puede introducirse en el estómago del niño sin traspasar su límite de distraibilidad - capacidad gástrica - que oscila entre los ochenta o trescientos gramos de leche o líquidos para un niño desde uno a seis meses.

Para extraer esa cantidad de leche del pecho de la mujer necesita el niño de doce a quince minutos de succión, no debiendo pasar nunca de veinte.

\footnotetext{
43. Fernández, Valentín. Topografía médica del concejo de Tapia de Casariego. Madrid: Imprenta de Julio Cosano; 1932, p. 101.

44. Villalaín, José. Topografía médica del concejo de Corvera de Asturias. Madrid: Imprenta de la Ciudad Lineal; 1925, p. 126.

45. Jove y Canella, José María. Topografía médica de Langreo. Madrid: Cosano; 1925, p. 176

46. Baillargeon, n. 3.
} 
Y en armonía con esto, el número y la distancia que separará unas tomas de otras se computará por el tiempo que el estómago tarde en digerir la cantidad de leche que puede contener en su interior. Esta duración o "capacidad digestiva”, está calculada en dos horas y media para la leche de mujer y en algo más para la leche de vaca» ${ }^{47}$.

Llama la atención la precisión y la rigidez al establecer las cantidades a ingerir, el tiempo de duración y la periodicidad de las tomas. Sin embargo, lo que más nos interesa remarcar es cómo la campaña emprendida no trataba solamente de promover la práctica de amamantar sino también de regularizar y supervisar la lactancia, ya fuese materna o artificial, siendo éste un aspecto en el que los médicos cosecharon notables éxitos en el medio plazo.

\section{Prácticas tradicionales en la crianza infantil}

Mientras a las madres más acomodadas se les recordaban sus deberes maternos y eran censuradas por recurrir a un ama de cría, obreras y campesinas fueron vistas como seres ignorantes y acusadas de matar «con muerte lenta a sus tiernos hijos» ${ }^{48}$ por alimentarlos sin seguir las pautas establecidas por la medicina. Establecer unas formas definidas de lactar, regularizar los horarios de las tomas y fijar las cantidades de leche que la criatura debía ingerir, formaba parte de un proyecto más amplio de normalización de la crianza infantil bajo presupuestos médicos. Puesto el cuidado de la infancia correspondían a las madres, éstas debían abandonar las prácticas tradicionales que empleaban para hacer frente a tal labor y dejarse guiar por consejo experto. La necesidad de este cambio se basaba en el planteamiento de que las madres eran las principales responsables de las altas cifras de mortalidad infantil:

«consideramos que de mil niños que nacen, más de la cuarta parte muere antes del primer año de su vida, víctimas casi siempre de una mal reglamentación alimenticia, hija de la tradicional ignorancia de nuestras madres» ${ }^{49}$.

47. Honorio García Álvarez. Al margen del hogar. Vulgarización médica a las madres. El Comercio. 5 Ene 1929.

48. Doctor Miguel Gil. Lectura para las madres. El Noroeste. 25 Jun 1906.

49. González, n. 38. 
Para los médicos, el nefasto proceder de las madres en cuanto a la alimentación era lo que ocasionaba más muertes. El estudio de las topografías médicas nos ofrece una interesante visión sobre el modo en que las madres se ocupaban de sus criaturas. Es cierto que esta imagen está tamizada por los autores de las mismas, lo que nos obliga a proceder con ciertas cautelas, pero esto no dejar de ser un elemento compartido por cualquier fuente a la que nos enfrentemos, ya sea escrita, oral o iconográfica, puesto que junto con los restos del pasado se encuentra la percepción subjetiva de quien los legó.

Hemos consultado doce topografías escritas por seis autores diferentes, médicos todos ellos, pero con percepciones ligeramente distintas. Esto nos permite confrontar visiones y acercarnos a cuáles eran las prácticas maternas de cuidado infantil, tratando de valorar en qué medida estaban condicionadas por el entorno social en el que tenían lugar.

De todas las «negligencias» maternas, las relativas a la alimentación eran las que según el criterio médico entrañaban más peligros. No sólo se trata de amamantar, sino del modo de hacerlo y del crucial momento del destete. En las topografías médicas se denuncia que las madres dan de comer a sus criaturas antes de los seis meses y que emplean alimentos totalmente inapropiados. En Avilés, cuya topografía médica data de 1913, José de Villalaín (1878-1939) denuncia que las madres de las aldeas del concejo tienen la costumbre «de darles de comer en los primeros meses» y añade que no sólo recurren a «la clásica papilla o las harinas cocidas» sino que «obligan a los niños a comer del pote familiar» ${ }^{50}$. La práctica no era exclusiva de esta zona sino que en el vecino concejo Corvera, el mismo doctor denunciaba una década más tarde, que se daba de comer a las criaturas antes del tiempo estipulado. El mayor perjuicio derivaba de recurrir a alimentos como las papillas «rabón» (pan rallado con manteca y azúcar) o incluso darles a probar del «pote» del que comían las personas mayores $^{51}$. Formas de proceder similares fueron detectadas por los autores de las topografías en otras partes de la región, en zonas mineras como Langreo (1925) y ciudades industriales como Gijón (1918), pero también en concejos rurales, como en Cabrales en el oriente (1921) o Tapia de Casariego en el occidente (1932).

50. Villalaín, José. Topografía médica del concejo de Avilés. Madrid: Establecimiento Tipográfico de los Hijos de Tello; 1913, p. 95.

51. Villalaín, n. 44, p. 127. 
La denuncia sobre las malas prácticas de crianza no se limitó a la alimentación, si bien fue éste un punto muy destacado por los médicos que establecían una relación entre la mala alimentación, las afecciones gastrointestinales derivadas de la misma y, como consecuencia última, la alta mortalidad infantil ${ }^{52}$. La carencia de higiene de las viviendas de que se culpaba también a las madres - por ser éstas responsables del cuidado del hogar - fue motivo de denuncia al entender que incidía negativamente en la preparación de los alimentos. En este sentido, los doctores coincidían en considerar que eran peores amas de casa las obreras que las mujeres del campo. Aunque se reconocía el duro trabajo de la mujer rural, se pensaba que podía compatibilizarlo con las tareas de la casa. En cambio, las mujeres que trabajaban fábricas dejaban más desatendida la higiene de su vivienda. Jove y Canella (1877-1931) en la Topografía médica del concejo de San Martín del Rey Aurelio, galardonada con premio Roel de la Academia de Medicina ${ }^{53}$ y publicada en 1922, veía en la poca dedicación de las mujeres al cuidado de su hogar una muestra de desmembración de la familia:

«La familia apenas si existe: minada en sus raíces, tiende a desaparecer (...) la mujer: niña aún, comienza a ocuparse de las labores industriales apropiadas, perdiendo en ese tiempo la oportunidad de un aprendizaje que la colocara, en la ocasión propicia, en circunstancias de saber hacerse cargo de su casa. Así, llega al matrimonio ignorando lo más esencial (...) sufrida y trabajadora, sumisa, llena de amor hacia los hijos, adolece del capitalísimo defecto señalado, por ignorancia, pues la familia encuéntrase sin el puntal más firme: la madre» ${ }^{54}$.

Como Jove y Canella, los médicos coincidían en señalar que las mujeres amaban profundamente a sus vástagos - como producto de su instinto maternal- pero pensaban que el amor era insuficiente si no se acompañaba de la debida instrucción, siendo éste un aspecto propio de la construcción de la maternidad científica. El breve relato de Jove y Canella muestra asimismo el contraste entre el prototipo representado por una familia de clase media en la cual la madre, formada en Economía doméstica y Puericultura,

52. Rodríguez Ocaña, Esteban. La construcción de la salud infantil. Ciencia, medicina y educación en la transición sanitaria en España. Historia Contemporánea. 1999; 18: 19-52 (23).

53. En honor del médico Faustino García Roel.

54. Jove y Canella, José María. Topografía médica del concejo de San Martín del Rey Aurelio. Madrid: Imprenta de la Ciudad Lineal; 1922, p. 64. 
se ocupa con toda dedicación y esmero del cuidado de sus criaturas y de su hogar, y la vida real de muchas mujeres asturianas de medios obreros que no disponían del tiempo ni de los recursos económicos necesarios para cumplir con semejantes ideales.

La poca higiene denunciada por los autores de las topografías no se limitaba a las viviendas, sino también a las ropas. De hecho, las formas de vestido tradicionales fueron otra de las prácticas a erradicar. En zonas distantes de la región como Ponga, Avilés o Luarca, se da cuenta de cómo las mujeres emplean el fajamiento para vestir a las criaturas. Este tipo de prácticas, documentadas ya en la Edad Moderna en diversas zonas de Europa, persistían en Asturias a comienzos del XX. ${ }^{55}$ En esencia, consistían en enrollar y apretar con ropas el cuerpo infantil. Además, en algunos concejos rurales se combinaba con el empleo de una cuna de reducidas dimensiones, llamada «tribeco» en Ponga y «escaniello» en Cabrales. En ambos casos se colocaba a los bebés en la cuna en posición de decúbito supino «atándoles fuertemente por medio de fajas, que pasan por los intersticios libres de las referidas tablas longitudinales, en forma que les impide todo movimiento» ${ }^{56}$. Felipe Portolá, autor de la topografía médica de Ponga, preguntó a las mujeres porqué «amarraban tanto» a las criaturas, a lo que respondieron que pretendían protegerlas del frío. Pero este argumento no convenció a Felipe Portolá que aseguraba que en países más norteños y fríos, como Alemania, Francia o Inglaterra, se empleaban ropas «más desahogadas» 57 .

La práctica del fajamiento ha sido considerada por Elizabeth Badinter como una prueba de dejadez en la atención infantil ${ }^{58}$. Sin embargo, Linda Pollock matiza esta consideración valiéndose de estudios antropológicos y entiende que el fajamiento es un recurso usual en sociedades en las que pocas personas adultas pueden encargarse de la vigilancia de las criaturas ${ }^{59}$. En este sentido, es necesario tener en cuenta que en el campo asturiano la mano de obra femenina era muy importante para las cosechas, el cuidado del ganado, la huerta y otras faenas como hacer el pan, ir a por agua o

55. Badinter, n. 1, p. 99-100.

56. Vilar, Joaquín. Topografía médica del concejo de Cabrales. Madrid: Establecimiento Tipográfico de El Liberal; 1921, p. 278.

57. Portolá Puyó, Felipe. Topografía médica del concejo de Ponga. Madrid: Establecimiento Tipográfico de los Hijos de Tello; 1915, 182.

58. Badinter, n. 1, p. 99-100.

59. Pollock, Linda. Los niños olvidados. Relaciones entre padres e hijos de 1500 a 1900. México: Fondo de Cultura Económica; 1983, p. 69. 
picar la leña para la cocina. Tal carga de trabajo hacía imposible que las madres pudieran ejercer una vigilancia continua sobre las criaturas como la exigida por los médicos. El recurso a esta práctica facilitaba a las mujeres compaginar crianza y trabajo: las campesinas no eran las ignorantes que los médicos veían en ellas, sino mujeres con unas condiciones de existencia no siempre percibidas con la suficiente agudeza por parte de los autores de las topografías. De igual manera, tampoco demostraban gran sensibilidad al denunciar, en estos mismos textos, la falta de baño diario de las criaturas o el hecho de someterlas a respirar los humos de las cocinas. Las viviendas rurales y buena parte de las urbanas carecían de baño y agua corriente. La vida se pasaba en las cocinas en el mundo rural, sobre todo en invierno, porque era el único espacio de la casa que contaba con una fuente calorífica. Este tipo de condicionantes no fueron tenidos en cuenta por los redactores de las topografías que, desde el ideal de la maternidad científica, acusaban a las mujeres de las clases humildes de ser madres ignorantes, negligentes y descuidas. Con todo, hubo algunos médicos más sensibles, que constituyen la excepción a la regla general. José de Villalaín fue uno de ellos:

«Muchas veces hemos oído que las mujeres de los obreros y las aldeanas pobres eran descuidadas para con sus hijos, y, con pena lo decimos, no puede ser de otro modo, dada la rudeza de su modo de vivir. Hay que considerar que la obrera tiene que atender a todos los quehaceres de su casa, preparar la comida del marido y llevársela a la fábrica (...) la aldeana pobre necesita trabajar y no puede dedicarse exclusivamente a su hijo. Este calificativo de descuidadas aplicado a las madres pobres y trabajadoras nos causa gran pena. ¿Qué más quisieran ellas que tener una criada, disponer de tiempo (...) y poder vestir con harapos limpios a sus niños!» ${ }^{60}$.

El ideal de maternidad científica fue proyectado por varones pertenecientes a las clases medias que, como señala Morata, llevaban consigo los valores propios de su clase social ${ }^{61}$. Esto explica los continuos desajustes que percibimos al contrastar las prácticas tradicionales de crianza con su construcción simbólica de la «madre ideal», representada por una mujer dedicada por entero al cuidado de su criatura en una vivienda confortable, 
convenientemente acondicionada y con varias habitaciones disponibles; una madre con un nivel educativo y económico que le permite comprar, leer y comprender los libros de Economía doméstica o Puericultura. Llama la atención, por ejemplo, el hecho de que se condene dormir en la misma habitación que las criaturas, cuando muchas casas obreras no disponían de más de una habitación en que pasaba la noche toda la familia.

En su estudio sobre Québec, Denyse Baillargeon explica que eran consideradas «malas madres» aquellas cuyos vástagos morían por enfermedades «evitables», término que también se utiliza en los diarios y revistas editados en Asturias cuando se ocupan de este tema ${ }^{62}$. Es importante el entrecomillado porque cabe preguntar hasta qué punto era posible evitar, en las condiciones de vida de los medios obreros y campesinos, la muerte de muchas criaturas. La reflexión médica concedió a la cuestión alimentaria el papel más destacado a la hora de explicar la mortalidad infantil, siendo éste un aspecto que en gran medida podía ser corregido por las madres evitando, entre otras cosas, dar de comer a las criaturas antes de tiempo. Pero conviene añadir algunas matizaciones al respecto: en primer lugar, como recoge Rodríguez Ocaña, no era ésta la causa principal de muerte en todos los lugares y, en este sentido, constata que se recurrió a datos de otros países cuando, por ejemplo, en ciudades como Bilbao, Barcelona o Valencia, se producían más muertes por afecciones respiratorias ${ }^{63}$. De igual manera, la topografía médica de Langreo muestra que, en el año 1923, la principal causa de muerte infantil en el concejo fue la bronquitis y la bronconeumonía (106 muertes) quedando en segundo lugar la gastritis y la gastroenteritis (89 muertes). Es cierto que podemos vincular la incidencia de afecciones respiratorias a situaciones de mala nutrición (al disminuir la capacidad de resistencia frente a la infección y aumentar las posibilidades de contagio) ${ }^{64}$ pero también puede relacionarse con la falta de medios económicos para proveerse de ropas de abrigo y mantas y para poder acceder a una vivienda convenientemente aislada del frío. Coincidimos, en definitiva, con Baillargeon cuando establece que se consideró a las madres responsables de la

\footnotetext{
62. Baillargeon, n. 3, p. 33

63. Rodríguez Ocaña, n. 52, p. 23.

64. Robles González, Elena; Pozzi, Lucia. La mortalidad infantil en los años de la Transición: una reflexión desde las experiencias italiana y española. Revista de Demografía Histórica. 1997; 15 (1): 165-200 (189).
} 
muerte de sus bebés, minimizando la importancia de la falta de recursos, siendo este elemento a nuestro juicio, el principal considerar ${ }^{65}$.

Para finalizar con las prácticas maternas tradicionales, vamos a detenernos, muy brevemente, en la cuestión de la atención a la criatura enferma. En este apartado, las madres fueron acusadas de dejarse llevar por la superstición acudiendo a curanderas - el llamado sector folk $k^{66}$ - en lugar de consultar a un médico. Al igual que en otras regiones del país, era frecuente pensar que las criaturas enfermas sufrían «mal de ojo», aunque en asturiano se utilizaban los términos «tar agüeyao». Las topografías médicas dan cuenta de estas prácticas, pero sus informaciones se pueden complementar con las procedentes de la encuesta realizada, en 1901, por el Ateneo de Madrid para conocer las costumbres de nacimiento, matrimonio y muerte en España. Se consideraba que una criatura estaba «agüeyada» cuando presentaba un aspecto enfermizo y delgadez extrema. Para remediar este mal se acudía a una curandera a que «le pase el agua». En un plano preventivo, para evitar que la criatura fuese víctima del mal de ojo se utilizaban diversos amuletos, que variaban según la zona. Si en Valencia, por ejemplo, era costumbre atar una cinta roja a la muñeca, en algunas zonas de Asturias se utilizaban «les puñeres», unas pulseras con pequeños trozos de azabache ${ }^{67}$. También era frecuente en el caso asturiano pensar que la criatura débil y sin apetito era portadora del «mal del filu». Para su cura se visitaba de igual forma a una curandera que llevaba a cabo todo un ritual narrado en sus distintas versiones por los encuestadores del Ateneo madrileño ${ }^{68}$.

El colectivo médico se oponía, como cabe suponer, a este tipo de remedios para el tratamiento de las enfermedades de la infancia. Por un lado, se trataba de la lucha de la ciencia contra la superstición y la ignorancia, pero también estaban protegiendo sus intereses en una etapa de desarrollo y consolidación de la profesión pediátrica ${ }^{69}$. Si para cuidar a la criatura sana

\footnotetext{
65. Baillargeon, n. 3.

66. Bernabeu Mestre, Josep. Transición sanitaria y evolución de la medicina (diagnóstico, profilaxis y terapéutica), 1885-1942. Revista de Demografía Histórica. 1998; 16 (2): 15-38 (21).

67. López Álvarez, Juaco; Lombardía Fernández, Carmen, eds. Costumbres de nacimiento, matrimonio y muerte en Asturias. Encuesta del Ateneo de Madrid 1901-1902. Gijón: Fundación municipal de Cultura, Educación y Universidad Popular; 1998, p. 30-35. Para conocer remedios contra el mal de ojo en otros lugares de España: Rodríguez Ocaña, n. 12, p. 155-156.

68. López Álvarez, Lombardía Fernández, n. 67, p. 35.

69. Como han puesto de manifiesto Rodríguez Ocaña y Perdiguero, n. 4, p. 305-309, el proceso de especialización médica que derivó en la consolidación de la medicina de la infancia se acompañó de una crítica implacable a los contenidos de la «cultura médica popular». También
} 
debían seguirse los dictados de la medicina y de la ciencia, para diagnosticar a la enferma debía acudirse al experto médico. Moreno Blasco resumió este principio en el segundo de sus diez mandamientos a las madres: «Jurarás no hacer caso a nadie más que al médico» ${ }^{70}$.

\section{Normalizar el cuidado infantil}

En los comienzos del siglo XX buena parte de las madres en Asturias se ocupaban de sus criaturas siguiendo las pautas tradicionales aprendidas de otras mujeres, como sus madres, abuelas, hermanas o vecinas. En pugna con estas prácticas, la medicina se iba abriendo paso, pero con diferentes ritmos atendiendo fundamentalmente a dos factores, la clase social y la procedencia, rural o urbana, de las madres. Cabe analizar los medios que los médicos y muy especialmente los pediatras, emplearon para hacer llegar a las mujeres - vistas todas ellas como madres potenciales- los preceptos de la Puericultura. Si la Pediatría era competencia exclusiva del doctor y tenía como objeto la atención a la criatura enferma, la Puericultura se encargaba del correcto desarrollo de la criatura sana y era una tarea encomendada a las madres aunque guiadas por el médico ${ }^{71}$. Las reglas prescritas por la Puericultura fijaban de modo estricto el cuidado infantil, los horarios de las comidas, los alimentos apropiados, el modo y frecuencia del baño, la vestimenta y el mobiliario de la habitación de la criatura junto con otros aspectos. Se trataba de todo un «encuadramiento» de la crianza ${ }^{72}$.

El periodo que estamos analizando es una etapa de transición en la implantación de la maternidad científica. Aunque sabemos que la historia es un devenir continúo, cabe establecer tres fases en lo que respecta a los recursos utilizados desde la medicina para lograr la transformación de las prácticas maternas en Asturias. La primera etapa, la situamos desde comienzos de siglo hasta 1913, a las puertas de la guerra europea. En este periodo, la letra impresa es la forma predominante de divulgación. Los periódicos

cabe recordar en este punto cómo parte de los contenidos rechazados científicamente y aceptados popularmente, procedían de la doctrina médica de años atrás.

70. Citado por: Portolá Puyós, Felipe. Topografía médica del concejo de Gijón. Madrid: Est. Tip. de El Liberal; 1918, p. 296.

71. Thébaud, n. 1, p. 119.

72. Baillargeon, n. 3. 
asturianos acogen secciones dedicadas «a las madres»o «para las damas», incluyendo consejos de higiene y cuidado de la infancia. Cabe notar que el diario republicano El Noroeste prestaba mayor atención a estos temas que la concedida por El Carbayón, de clara orientación conservadora. Esto nos lleva a recordar que el proyecto de redefinición de la maternidad estaba encabezado por medios reformistas que veían en las mujeres una potencial ayuda para mejorar y armonizar la sociedad, comenzando por la familia, en la que debían establecer normas y horarios. El Noroeste de Gijón publicó en 1904, íntegramente, la Cartilla higiénica del doctor Rafael Ulecia, la misma que éste repartía de forma gratuita en el Consultorio Infantil que regentaba en Madrid. La cartilla se componía de doce consejos, de los cuales cuatro se referían a la alimentación y lactancia y el resto a la dentición, peso, vacunas, paseos, baño diario y a horas de sueño. Para persuadir a las madres de seguir los consejos se les exhortaba a cumplir estas «sencillas reglas» o a pagar «con lágrimas»su desobediencia ${ }^{73}$. Los médicos establecían normas mientras que las madres debían limitarse a obedecerlas. Otros pediatras de reconocido prestigio tuvieron su espacio en el periódico gijonés. Nos referimos al doctor Martínez Vargas (1861-1948) que publicó varios artículos sobre «consejos a las madres» ${ }^{74}$. Desde el último tercio del XIX, la literatura de «consejos a las madres» se editaba con cierta profusión España ${ }^{75}$. Debemos entender que esta literatura convivía en los inicios del siglo pasado con la divulgación a través de la prensa, medio de comunicación crucial en la etapa que estamos considerando. Junto a los diarios de grandes tiradas y contenidos generalistas, las revistas especializadas editadas por los medios higienistas asturianos destinaron buena parte de sus páginas a formar a las madres. Así, la Revista Popular de Higiene, publicada en Oviedo entre 1906 y 1910 bajo la dirección del doctor Arturo Buylla, dedicó varios artículos al «arte de criar niños», buena parte de los cuales fueron escritos por la maestra e higienista María Asunción Izquierdo.

Aunque los diarios eran más accesibles debido a su menor coste que los libros de higiene infantil y consejos a las madres, la divulgación a través de medios escritos tenía la limitación de que una parte sustantiva de las

\footnotetext{
73. Cartilla higiénica del Dr. Ulecia. El Noroeste. 11 Jul 1904.

74. Doctor Martínez Vargas. Consejos a las madres. El termómetro en las familias. 3 Abr 1911.

75. Palacio Lis, Irene. Consejos a las madres»: autoridad, ciencia e ideología en la construcción social de la función materna. Una mirada al pasado. Sarmiento: Anuario galego de historia de la educación. 2003; 7: 61-80 (68).
} 
mujeres no sabían leer (el analfabetismo femenino en Asturias era del 64,9 en 1900, si bien había descendido a 31,65 en 1930) ${ }^{76}$ o carecían del tiempo y la motivación necesaria para hacerlo. En este sentido, el doctor Luis Azcoitia explicaba en una columna de prensa publicada en 1912 que las cartillas de consejos a las madres no daban el resultado buscado porque «las mujeres del pueblo no tienen tiempo de leer» y además «son poco aficionadas a la lectura sobre todo cuando ésta tiene un carácter científico» ${ }^{77}$. Debido a esto, y al propio interés médico por llegar a mujeres de los estratos sociales populares, se pusieron en marcha otro tipo de iniciativas con las que se iniciaría la segunda fase que estamos considerando y que situamos entre 1914 y 1919. En estos años se planifican en Asturias nuevos proyectos de divulgación mediante cursos, conferencias y premios, tomando la sociedad de Cultura e Higiene de Gijón la delantera en las iniciativas. Junto con la publicación artículos de Puericultura en la revista de la asociación (algunos con la firma de afamados pediatras como Tolosa Latour) organizó charlas en sus distintas sedes repartidas por los barrios de la ciudad. Además, con la ayuda del pedagogo y eugenista Luis Huerta $(1889-1975)^{78}$, planeó la organización de un concurso para premiar a la madre «que presente mejor ejemplar de niño bien criado, conforme a las prescripciones de la ciencia ${ }^{79}$. De igual forma, Cultura e Higiene con la colaboración de Luis Huerta, proyectó la creación de una escuela de madres que «habría de servir para ir deshaciendo paulatinamente los crasos errores de tanta pobre madre ${ }^{80}$. La escuela tenía previsto formar a las mujeres desde una amplia concepción de la Puericultura, abarcando desde la vida intrauterina a la adolescencia, pasando por la atención la criatura recién nacida, la lactancia y las etapas preescolar y escolar. Si bien ni el premio a la madre ejemplar ni la escuela de madres se llevaron a efecto, ya que Luis Huerta se ausentó de Gijón con destino a Bruselas por una beca del Ministerio de Instrucción

\footnotetext{
76. García Galán, n.15, p. 55.

77. Luis Azcoitia. Las Gotas de Leche. Del personal y otras consideraciones. El Carbayón. 15 Sep 1912.

78. Diego, Carmen. Luis Huerta: maestro e higienista. Oviedo: KRK; 2006.

79. De nuestro programa. Concursos de Puericultura y Exposiciones de niños de pecho. Cultura e Higiene. 11 Oct 1913. Este tipo de eventos se organizaban en Francia desde finales del siglo XIX, si bien entraron en decadencia a partir de la tercera década del siglo pasado al considerar los médicos que animaban a las madres a engordar en exceso a sus criaturas: Rollet, n. 3, p. 155-156.
}

80. De nuestro programa, n. 79 . 
Pública, son claras muestras de un cambio de orientación en la difusión de la maternidad científica. Ya no se trataba sólo de formar a una minoría de mujeres instruidas y de clase media, sino de llegar a madres de clase obrera para lo cual eran necesarias estrategias novedosas. En esta etapa se pone en marcha la Gota de Leche de Oviedo que es, en sí misma, un medio de formación privilegiado para los médicos gracias a la comunicación directa que pueden tener con las madres.

La tercera etapa se inicia en 1919 y nos lleva hasta los comienzos de la Segunda República, en 1931, suponiendo toda una eclosión de iniciativas para la formación de las madres. El protagonismo corre a cargo del Instituto de Puericultura de Gijón y de su promotor, Avelino González. Para contar con el respaldo social necesario a su proyecto, González inició una campaña en los medios de prensa en 1919 publicando una serie de artículos sobre lactancia, nodrizas, mortalidad infantil y Puericultura. El centro gijonés se inaugura en 1925 (adelantándose a la apertura de la Escuela Nacional de Puericultura, que había sido creada en 1923, pero no fue inaugurada hasta 1926) y contaba en sus comienzos con una Gota de Leche y un Consultorio infantil. A estos servicios se fueron sumando otros como la Casa-cuna (1930), la Sala de maternidad y la Consulta prenatal (1930), la Escuela Provincial de Puericultura, que formaba niñeras tituladas, enfermeras y visitadoras sanitarias (1927) y la Escuela de madres (1929) ${ }^{81}$. El centro fue pionero y ejemplar en el conjunto de España y se convirtió en el principal irradiador de las nuevas prácticas maternas en la región. El contacto directo del personal especializado con las madres, tanto del propio Avelino González como de las enfermeras y especialmente de las visitadoras - con Virginia Leal al frente- que recorrían los hogares de las familias solicitantes de los servicios, fueron sin duda, estrategias de gran efectividad para la instrucción materna. La obediencia era un requisito fundamental para poder disfrutar de los recursos de la institución, de forma que a las madres que no seguían las directrices marcadas por el médico, eran retiradas del servicio. A modo de ejemplo citaremos el caso de una madre expulsada de la Gota de leche porque daba papillas a su bebé sin permiso del doctor ${ }^{82}$. Los carteles fueron otro recurso empleado para divulgar mensajes destinados a las madres. Hemos comprobado cómo algunos de los carteles de Gijón

81. García Galán, n. 37, p. 123-127.

82. Solicitudes de admisión, n. 25. 
fueron compartidos con centros de puericultura de otras partes del país, como el Instituto de Puericultura de Reus ${ }^{83}$. El Instituto de Puericultura de Gijón editó además cartillas sanitarias con recomendaciones de lactancia y crianza infantil. Llevaba también un registro de las criaturas acogidas en el servicio de Gota de Leche y en el Consultorio infantil, compuesto por una única hoja en la que las visitadoras tomaban nota de las condiciones de la vivienda, salario del padre y de la madre y otras informaciones de carácter más social que médico, para que Avelino González, como director del centro, pudiese dictaminar si correspondía conceder el servicio. No nos consta que se editasen en Asturias cartillas sanitarias como las que ha analizado Rollet en Francia, en las que las madres debían tomar nota de la evolución de sus criaturas para que posteriormente el médico interpretase los datos ${ }^{84}$. Posiblemente porque este tipo cartillas comenzaron a publicarse a finales del XIX, cuando todavía las madres eran vistas como cooperadoras del doctor mientras que, en nuestro caso, nos encontramos una fase posterior, en la que las mujeres debían limitarse a obedecer. Mientras el mensaje fue dirigido hacia madres de clase media (a lo largo del siglo XIX y comienzos del XX) se consideró que podían formarse de manera autónoma mediante la lectura de textos médicos y convertirse en auxiliadoras del médico. Sin embargo, cuando lo que se intenta es cambiar la conducta de las madres obreras, se incrementan y modifican las iniciativas: desde conferencias, premios y cursos, hasta coacciones directas a través de servicios como la Gota de Leche.

Este tipo de iniciativas cosecharon buenos resultados, logrando una reducción de las tasas de mortalidad infantil en el ámbito urbano, sobre todo en ciudades como Gijón dotadas de estos servicios. Sin embargo, la divulgación de la Puericultura en las aldeas era más problemática. Como reconocía Villalaín en la Topografía médica de Corvera, la aldea no estaba «a la altura de las grandes poblaciones, donde es mayor el contacto del pueblo con las Gotas de Leche o con los pediatras especializados». ${ }^{85}$ En las zonas rurales asturianas, la emigración retornada jugó un papel fundamental. El propio José de Villalaín narraba en la Topografía médica de Avilés cómo

83. Chamizo, Carmen. La Gota de Leche y la Escuela de Enfermeras. Gijón: edición de la autora; 1999, p. 175-177; Arnavat, Albert; Pagés, Montserrat y Amorós, Xavier. L'Institut de Puericultura Dr. Frías «La Gota de Llet». Reus 1919-1994. Reus: Ajuntament de Reus; 1995.

84. Rollet, n. 3.

85. Villalaín, n. 44, p. 94. 
las emigrantes que habían vivido en Estados Unidos regresaban trayendo consigo las costumbres de crianza de aquél país. Los nuevos usos tenían buena acogida ente las mujeres que no habían salido del concejo ${ }^{86}$. La emigración jugaba así un papel modernizador de las costumbres que afectaba, también, a las prácticas maternas y el contacto, comunicación y aprendizaje entre mujeres resultaba un medio de lo más efectivo.

\section{A modo de conclusión}

Los cambios en el ejercicio de la maternidad, desde los modos tradicionales a la supervisión médica, suponían en gran medida la pérdida de control por las mujeres de su propia maternidad. La consigna difundida en las primeras décadas del siglo pasado afirmaba que para lograr la supervivencia y robustez de las criaturas, era imprescindible obedecer al experto médico varón. Sin embargo, las mujeres no siempre se limitaron a acatar la autoridad médica, sino que renegociaron sus directrices para poder acoplarlas a su situación personal. Si mujeres instruidas y de clase media optaban por combinar la lactancia materna con el biberón, pese a estar totalmente proscrito para las que podían lactar, campesinas y obreras no podían llevar a cabo las recomendaciones porque sus condiciones materiales de vida y la carga de trabajo que tenían que afrontar cada día no se lo permitían. En definitiva, los médicos buscaron madres dóciles, pero no siempre las encontraron: imaginaron madres ideales y se toparon con mujeres reales. 
